\title{
P61 Comparison of Two Oscillometric Technics for Measuring Pulse Wave Velocity
}

\author{
Béla Benczúr ${ }^{1, *}$, Renata Bocskei ${ }^{2}$ Attila Cziraki ${ }^{2}$ \\ ${ }^{1}$ Balassa Janos County Hospital, Ist Department of Internal Medicine (Cardiology/Nephrology), Szekszard, Hungary \\ ${ }^{2}$ Heart Institute, University of Pecs, Pecs, Hungary
}

\begin{abstract}
It has been proven that aortic pulse wave velocity (aoPWV), the measure of arterial stiffness is a strong and independent predictor of both cardiovascular events and all-cause mortality. Beyond the "gold standard" cfPWV (carotid-femoral) a plenty of methods are available for measuring PWV but the interpretation of their results are problematic and not interchangeable.

Patients and Methods: Our aim was to assess the association and agreement of two oscillometric methods; the upper armcuffed invasively validated Arteriograph system and the brachial-ankle PWV (baPVW) measurement employed by the automatic BOSO-ABI system which operates simultaneous cuff-measurements on both extremities. 157 apparently healthy individuals of both sexes (mean age was $44.3+9.3$ ys; 54 male and 103 female) were examined in this study.

Results: Mean PWV was significantly higher with BOSO $(11.76+1.52 \mathrm{~m} / \mathrm{s})$ than Arteriograph $(8.45+1.71 \mathrm{~m} / \mathrm{s})$. The two different measurement modalities demonstrated moderate linear correlation (The Pearson's test of correlation coefficient $r=0.391, p<0.001)$. The lack of agreement between the two methods is confirmed also by the Bland-Altman plot.

Conclusion: Both methods are simple and easy to use and offer a user independent automatic assessment of PWV. The difference of the measured values derived from the different path length the two methods use.

(c) 2019 Association for Research into Arterial Structure and Physiology. Publishing services by Atlantis Press International B.V. This is an open access article distributed under the CC BY-NC 4.0 license (http://creativecommons.org/licenses/by-nc/4.0/)
\end{abstract}

